\title{
Expression of the Phenotypic Abnormality of Platelet-Type von Willebrand Disease in a Recombinant Glycoprotein Ib $\alpha$ Fragment
}

\author{
Mitsuru Murata, Susan R. Russell, Zaverio M. Ruggeri, and Jerry Ware \\ Department of Molecular and Experimental Medicine/Committee on Vascular Biology, Roon Research Center for Arteriosclerosis and \\ Thrombosis, Division of Experimental Hemostasis and Thrombosis, The Scripps Research Institute, La Jolla, California 92037
}

\begin{abstract}
The platelet GP Ib-IX receptor supports platelet adhesion and activation by binding to $\mathrm{vWf}$ in the exposed subendothelial matrix. An abnormal GP Ib-IX complex exists in platelet-type or pseudo-von Willebrand disease and has a characteristic increased affinity for soluble $v W f$ resulting in impaired hemostatic function due to the removal of larger $v W f$ multimers from the circulation. Genetic studies within an afflicted family have demonstrated that the disease is linked to a Gly ${ }^{233} \rightarrow$ Val amino acid substitution within the $\alpha$-subunit of the oligomeric GP Ib-IX complex (Miller, J. L., D. Cunningham, V. A. Lyle, and C. L. Finch. 1991. Proc. Natl. Acad. Sci. USA. 88:47614765). To evaluate the functional consequences of this mutation, we constructed a recombinant analogue of the $\alpha$-subunit of GP Ib containing $\mathrm{Val}^{233}$. Experiments comparing molecules with either $\mathrm{Gly}^{233}$ or $\mathrm{Val}^{233}$ revealed that the Val substitution generates a molecule with increased affinity for $\mathrm{vWf}$. The recombinant fragment reproduces the functional abnormality of the GP Ib-IX complex in platelet-type von Willebrand disease, thus establishing the molecular basis of the bleeding disorder within this family. Moreover, it becomes apparent that structural elements responsible for the regulation of hemostasis through modulation of $\mathbf{v W f}$ affinity for platelets reside within the $\alpha$-subunit of the GP Ib-IX complex. (J. Clin. Invest. 1993. 91:2133-2137.) Key words: thrombosis • platelet adhesion • genetic disease $\bullet$ von Willebrand factor $\bullet$ hemostasis
\end{abstract}

\section{Introduction}

The adhesion of platelets onto an altered vascular surface is an early event in thrombogenesis supported by specific platelet membrane receptors and their adhesive ligands. Among the latter, vWf binds to two sites on the platelet membrane, the GP Ib-IX and the GP IIb-IIIa receptor complexes (1-4). vWf as a soluble component of plasma has an unmeasurable affinity for unstimulated circulating platelets, thus, specific mechanisms must be responsible for initiation of the interaction between vWf and platelets at sites of vascular injury. In the temporal sequence of interactions leading to thrombus formation, the recognition of surface-bound vWf by GP Ib is the first necessary step leading to irreversible adhesion under high shear stress (5).

Address correspondence to Jerry Ware, Ph.D., SBR 8, The Scripps Research Institute, 10666 North Torrey Pines Road, La Jolla, CA 92037.

Received for publication 10 April 1992 and in revised form 21 December 1992.

J. Clin. Invest.

(C) The American Society for Clinical Investigation, Inc.

$0021-9738 / 93 / 05 / 2133 / 05 \$ 2.00$

Volume 91, May 1993, 2133-2137
It has been proposed that the regulation of $\mathrm{vWf}$ binding to GP Ib-IX may depend upon specific functional conformations acquired by the ligand and/or the receptor either as a consequence of rheological conditions or, in the case of vWf, as a result of being surface-bound within the subendothelial matrix (6-8). Indeed, the possibility of regulating affinity through conformational changes in vWf has been recently supported by the demonstration that a single amino acid substitution results in a subtype of von Willebrand disease, type IIB, in which an abnormal soluble vWf molecule has an increased affinity for a normal GP Ib-IX complex (9). Conversely, structural alterations in the platelet GP Ib-IX complex are presumed to be the underlying molecular basis of platelet-type or pseudo-von Willebrand disease in which an aberrant receptor has increased affinity for normal vWf $(10,11)$. Both platelet-type von Willebrand disease and type IIB von Willebrand disease are clinically similar but the underlying molecular bases are different, one resulting from a hyperfunctional ligand (type IIB von Willebrand disease ) and the other from a hyperfunctional platelet receptor (platelet-type von Willebrand disease). This implies that conformational changes in both GP Ib and $\mathrm{vWf}$ may be relevant to platelet thrombus formation.

A variant GP Ib-IX complex resulting in platelet-type von Willebrand disease has been associated with a single amino acid substitution, Gly ${ }^{233} \rightarrow$ Val, within the $\alpha$-subunit of the GP Ib-IX complex (12). However, the GP Ib-IX complex is a three-subunit receptor and even though the $\alpha$-subunit (GP $\mathrm{Ib} \alpha$ ) contains the binding site for vWf, it is not known if the other two subunits of the complex contribute to the in vivo modulation of binding to vWf $(13,14)$. Thus, without supporting evidence that the other components of the receptor complex are normal, it is impossible to conclude with certainty that the $\alpha$-subunit containing Val at position 233 is responsible for increased in vivo affinity for vWf. In this report we demonstrate that a GP Ib $\alpha$ recombinant analogue containing the Gly $^{233} \rightarrow$ Val substitution displays increased binding affinity for normal vWf. The results provide direct evidence that a GP Ib $\alpha$ fragment can functionally mimic the abnormal receptor associated with platelet-type von Willebrand disease and support the concept that conformation changes associated with the $\alpha$-subunit of the GP Ib-IX receptor complex may be an important mechanism in the regulation of hemostasis.

\section{Methods}

Construction of recombinant plasmids and generation of stable cell lines. A recombinant plasmid, pMW2, has been previously reported (15) and directs the secretion from Chinese hamster ovary (CHO-K1 ${ }^{1}$ cells of a GP Ib $\alpha$ fragment composed of residues $\mathrm{His}^{1}-\mathrm{Ala}^{302}$. This secreted fragment corresponds to a previously characterized $45-\mathrm{kD}$

1. Abbreviation used in this paper: $\mathrm{CHO}-\mathrm{K} 1$, Chinese hamster ovary. 
tryptic fragment from the amino terminus of GP Ib $\alpha$ containing the binding site for $\mathrm{vWf}(13,16,17)$. pMW2 was constructed from a genomic fragment of the GP Ib $\alpha$ gene inserted into pCDM8 ${ }^{\text {neo }}$, a modified version of $\mathrm{pCDM} 8$ containing a neomycin resistance gene (18). The secreted GP Ib $\alpha$ fragment containing native sequence instrinsically assembles into a conformation recognized by a series of anti-GP Ib $\alpha$ monoclonal antibodies and binds von Willebrand factor in the presence of modulators, either ristocetin or botrocetin (15). The monoclonal antibodies used in these studies, LJ-Ib $\alpha 1$, LJ-Ib1, LJ-P3, and LJP19 have been previously described $(13,16,17)$. A rabbit antiserum obtained by immunization with a synthetic peptide corresponding to GP Ib $\alpha$ residues $\mathrm{Gly}^{271}-\mathrm{Glu}^{285}$ was also used.

pMW2/G233V is identical to pMW2 except that the Gly ${ }^{233}$ codon (GGT) of pMW2 was changed to a Val ${ }^{233}$ codon (GTT). Site-directed mutagenesis was performed on uracil-containing template derived from a recombinant filamentous phage containing the GP Ib $\alpha$ coding sequence of pMW2 (19). After mutagenesis, the $\alpha$-subunit coding sequence was checked by DNA sequence analysis to verify that only codon 233 had been altered. The mutant GP Ib $\alpha$ fragment was subsequently cloned into pCDM8 ${ }^{\text {neo }}$.

pMW2 and pMW2/G233V were separately transfected into CHO$\mathrm{K} 1$ cells using a calcium phosphate transfection procedure (20). The CHO-K1 cells were cultured in DMEM supplemented with $2.5 \mathrm{mM}$ L-glutamine, $0.5 \mathrm{mM}$ nonessential amino acids, and $10 \%$ heat-inactivated fetal calf serum (Whittaker Bioproducts, Walkersville, MD). After transfection, cells were cultured in the presence of $0.8 \mathrm{mg} / \mathrm{ml}$ Geneticin (Life Technologies Inc., Grand Island, NY) to select for stable integration of the expression plasmid. Approximately $14 \mathrm{~d}$ after transfection isolated $\mathrm{CHO}-\mathrm{K} 1$ colonies were expanded and assayed for the presence of GP Ib $\alpha$ antigen in the culture medium. The anti-GP $\mathrm{Ib} \alpha$ monoclonal antibody, $\mathrm{LJ}-\mathrm{Ib} \alpha 1$, recognizes an epitope within residues 1-237 and was used in a dot-blot analysis in parallel with a rabbit antiserum obtained from immunization with the Gly ${ }^{271}-\mathrm{Glu}^{285}$ synthetic peptide.

${ }^{125} \mathrm{I}-\mathrm{vWf}$ binding to recombinant GP Ib $\alpha$ fragments. Culture medium from cells transformed by pMW2 and pMW2/G233V was assayed for the quantity of GP Ib $\alpha$ antigen by reacting with $\mathrm{LJ}-\mathrm{Ib} \alpha 1$ or the polyclonal antiserum derived from the $\mathrm{Gly}^{271}-\mathrm{Glu}^{285}$ peptide. The relative reactivities of $\mathrm{LJ}-\mathrm{Ib} \alpha 1$ and the anti-Gly ${ }^{271}-\mathrm{Glu}^{285}$ serum were similar as assessed by serial twofold dilutions of the culture media containing each recombinant fragment. This implies that the Gly ${ }^{233} \rightarrow$ Val substitution has no effect on the epitope(s) recognized by each antibody. In fact, the chosen cell lines from each transformation secreted indistinguishable levels of GP Ib $\alpha$ antigen so that dilutions were not required in order to obtain comparable levels of antigen for binding studies. Serum-free culture media for binding analyses was harvested after a $24 \mathrm{~h}$ incubation from confluent flasks in which the cells were prewashed three times with DMEM.

The binding assay to evaluate vWf interaction with the recombinant fragments has been described in detail (15). In this assay the receptor fragment is immobilized on a nitrocellulose membrane and the radiolabeled ligand, ${ }^{125} \mathrm{I}-\mathrm{vWf}$, is filtered through the membrane using a vacuum generated by a peristaltic pump. This assay was chosen to mimic the situation of the GP Ib-IX-V complex inserted in the platelet membrane, and indeed, ${ }^{125} \mathrm{I}-\mathrm{vWf}$ binding to nitrocellulose was shown to be specific for the recombinant GP Ib $\alpha$ fragment using monoclonal antibodies that inhibit vWf binding to platelet $\mathrm{GP} \mathrm{Ib}(15)$. In addition, the binding assays are performed under conditions whereby the nitrocellulose is saturated with each recombinant GP Ib $\alpha$ fragment, such that, increasing the recombinant fragment concentration does not result in increased vWf binding.

The binding was performed by immobilizing the recombinant fragments onto a nitrocellulose membrane using a commercially available apparatus designed for an enzyme-linked immunofiltration technique (ELIFA; Pierce Chemical Co., Rockford, IL). Culture medium (200 $\mu$ l) was vacuum-drawn through the nitrocellulose membrane by a peristaltic pump. After binding the culture medium, the binding capacity of the nitrocellulose was saturated by filtering $600 \mu$ l of Hepes-BSA buffer ( $20 \mathrm{mM}$ Hepes, pH 7.4; $150 \mathrm{mM} \mathrm{NaCl}$; 1\% BSA) through the membrane. After this blocking step, a $50-\mu 1$ mixture of ${ }^{125} \mathrm{I}-\mathrm{vWf}$ with the indicated concentration of ristocetin or botrocetin (Sigma Immunochemicals, St. Louis, MO) was filtered through the membrane. The vWf was labeled via the iodination procedure of Fraker and Speck (21). For the ristocetin and botrocetin-dependent binding curves (Fig. 2), a final wash of $200 \mu$ l Hepes-BSA buffer was used. For determining the amount of ${ }^{125} \mathrm{I}-\mathrm{vWf}$ bound to each sample, a nitrocellulose disc corresponding to each application well was counted in a $\gamma$-scintillation spectrometer. Under the described conditions, the binding of ${ }^{125} \mathrm{I}-\mathrm{vWf}$ to the GP Ib $\alpha$ fragment was not reversible. Thus, we refrained from using Scatchard type analysis to obtain "apparent" dissociation constants and to extrapolate "apparent" maximal binding at saturation. "True" values for these parameters can only be obtained under conditions of equilibrium binding.

\section{Results}

Expression of recombinant GP Ib $\alpha$ analogues. To evaluate the structural and functional consequence of a Gly ${ }^{233} \rightarrow$ Val substitution within GP Ib $\alpha$, we constructed an expression plasmid, pMW2/G233V, that is identical to the previously reported plasmid, pMW2, except that it contains a glycine to valine codon substitution at position 233 . As originally reported (15), pMW2 directs the secretion from CHO-K1 cells of a soluble amino-terminal fragment of GP Ib $\alpha$ containing residues His ${ }^{1}$ $\mathrm{Ala}^{302}$. Stable CHO-K1 cell lines were established after transfection with pMW $2 / \mathrm{G} 233 \mathrm{~V}$ and secretion of GP Ib $\alpha$ antigen was confirmed by immunoblotting with anti-GP Ib $\alpha$ monoclonal antibodies. A panel of conformation-dependent monoclonal antibodies, each recognizing distinct epitopes within the $\mathrm{NH}_{2}$-terminal domain of GP Ib $\alpha$, were tested for their ability to interact with culture media containing the $\mathrm{Val}^{233}$ mutant fragment. The immunoreactivity of media containing the mutant fragment was compared to media taken from cells secreting the normal GP Ib $\alpha$ fragment and nontransformed CHO-K1 cells. A nondenaturing dot-blot analysis was used since the epitopes recognized by several of the antibodies are sensitive to denaturation. The results demonstrate that the mutant fragment is secreted at levels similar to the fragment containing normal GP $\mathrm{Ib} \alpha$ sequence and, with respect to the antibodies tested, the two are immunologically indistinguishable (Fig. 1).

Functional consequences of a Gly ${ }^{233} \rightarrow$ Val substitution. Preliminary studies were performed to determine the amount of ristocetin required to obtain maximal binding at a fixed vWf concentration (Fig. 2, upper graph). Both the mutant fragment and the fragment with normal sequence had maximal binding when tested with $2 \mu \mathrm{g} / \mathrm{ml}$ of $\mathrm{vWf}$ at $\sim 0.7 \mathrm{mg} / \mathrm{ml}$ ristocetin. However, at lower doses of ristocetin $(0.2-0.5 \mathrm{mg} / \mathrm{ml})$ the amount of ${ }^{125} \mathrm{I}-\mathrm{vWf}$ bound to the mutant fragment was markedly increased as compared to $\mathrm{vWf}$ bound to the normal fragment. For example, the Gly ${ }^{233} \rightarrow$ Val mutant fragment bound fourfold more $\mathrm{vWf}$ using ristocetin at $0.25 \mathrm{mg} / \mathrm{ml}$. In contrast, vWf binding supported by increasing amounts of botrocetin was essentially identical for both fragments (Fig. 2, lower graph).

The apparent enhanced interaction between $\mathrm{vWf}$ and the mutant fragment was further investigated by evaluating the effect of increasing $\mathrm{vWf}$ concentration on the amount of $\mathrm{vWf}$ bound in the presence of different amounts of ristocetin. A representative experiment using $0.34 \mathrm{mg} / \mathrm{ml}$ of ristocetin is illustrated in Fig. 3 (upper graph), demonstrating that the mutant fragment binds more vWf than the control native frag- 


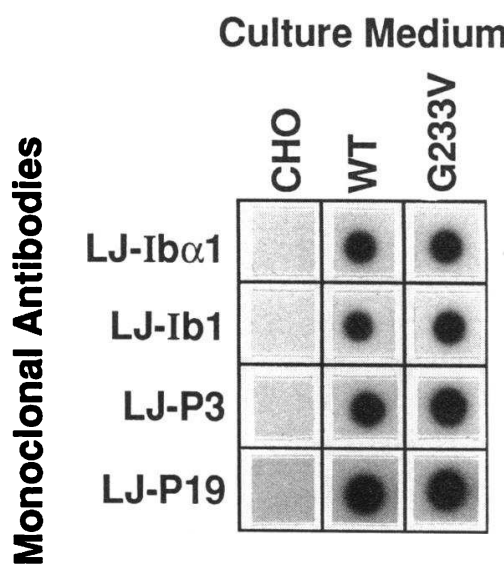

Figure 1. Immunological analysis of recombinant GP Ib $\alpha$ fragments. Serum-free culture medium $(200 \mu \mathrm{l})$ from nontransformed CHO$\mathrm{K} 1$ cells $(\mathrm{CHO})$, cells transformed with pMW2 $(W T)$ or pMW2/G233V $(G 233 V)$ was immobilized onto nitrocellulose membranes (dot-blot) and reacted with a panel of murine monoclonal antibodies recognizing distinct epitopes within the $\mathrm{NH}_{2}$ terminus of the $\alpha$-subunit of GP Ib. LJ-Ib $\alpha 1$ recognizes an epitope present on reduced GP Ib $\alpha$ within the first 237 residues; accordingly samples reacted with $\mathrm{LJ}-\mathrm{Ib} \alpha 1$ were reduced with $50 \mathrm{mM}$ dithiothreitol before spotting on nitrocellulose. The other antibodies each recognize epitopes that are sensitive to denaturation and/or reduction and so culture medium was spotted onto the nitrocellulose without prior treatment. The expressed GP Ib $\alpha$ fragments correspond to residues, $\mathrm{His}^{\mathrm{L}}$-Ala ${ }^{302}$. Bound anti-GP Ib $\alpha$ monoclonal antibody was detected using an ${ }^{125} \mathrm{I}$-labeled rabbit anti-mouse IgG and subsequent autoradiography. A photograph representing the autoradiograph is shown.

ment at any concentration of vWf tested. Thus, the Gly ${ }^{233} \rightarrow$ Val mutant fragment bound 10 -fold more vWf than the corresponding normal fragment control using $5 \mu \mathrm{g} / \mathrm{ml}$ of $\mathrm{vWf}$ and $0.34 \mathrm{mg} / \mathrm{ml}$ of ristocetin (Fig. 3, upper graph). Neither GP Ib $\alpha$ fragment was able to bind vWf in the absence of ristocetin. In contrast, using ristocetin at $1 \mathrm{mg} / \mathrm{ml}$ both the mutant fragment and the normal fragment exhibited similar binding properties

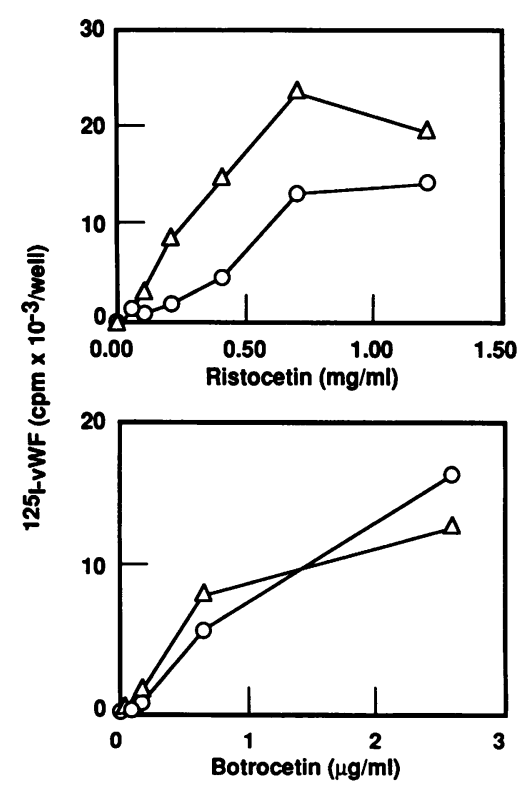

Figure 2. Dose-dependent effect of exogenous modulators on ${ }^{125} \mathrm{I}-\mathrm{vWf}$. binding to recombinant GP Ib $\alpha$ fragments. ${ }^{125} \mathrm{I}$ $\mathrm{vWf}(2 \mu \mathrm{g} / \mathrm{ml}$; sp act $6.95 \times 10^{8} \mathrm{cpm} / \mathrm{mg}$ ) was incubated for 30 min at room temperature with the indicated concentrations of ristocetin ( upper graph) or botrocetin (lower graph). At the end of the incubation, each mixture $(50 \mu \mathrm{l})$ was vacuum-drawn over a 5-min period through a demarcated circular area of a nitrocellulose membrane containing serum-free culture media with identical

amounts of normal GP Ib $\alpha$ fragments $(W T)$, the mutant fragment $(G 233 \mathrm{~V})$, or serum-free culture media from nontransformed CHO$\mathrm{K} 1$ cells. After washing once, membrane-bound radioactivity was counted by $\gamma$-scintillation spectrometer. Each point represents the value obtained by subtracting the amount of radioactivity bound by culture medium from nontransformed $\mathrm{CHO}-\mathrm{K} 1$ cells from that amount bound to the culture medium from the two transformed cell lines. $\circ, \mathrm{WT} ; \Delta, \mathrm{G} 233 \mathrm{~V}$.

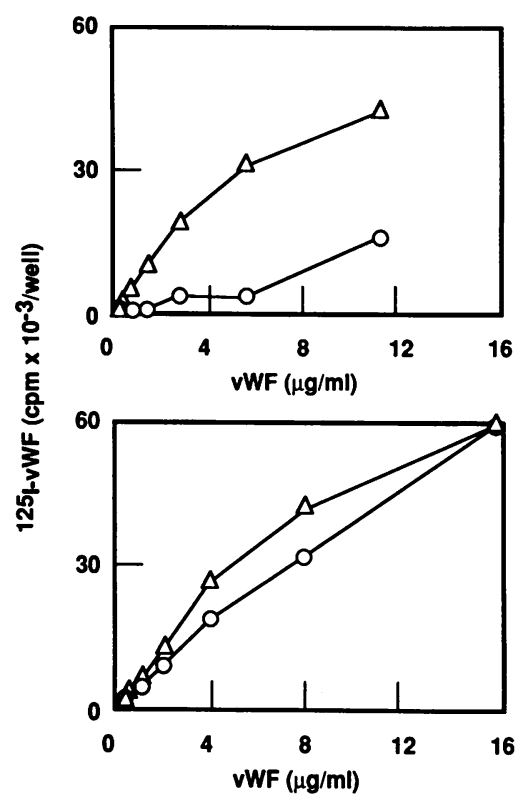

Figure 3. ${ }^{125} \mathrm{I}-\mathrm{vWf}$ binding to recombinant GP Ib $\alpha$ fragments. ${ }^{125} \mathrm{I}-\mathrm{vWf}$ at a final concentration of $0.0625-16 \mu \mathrm{g} / \mathrm{ml}$ was incubated with either $0.34 \mathrm{mg} / \mathrm{ml}$ ( upper graph) or $1 \mathrm{mg} / \mathrm{ml}$ (lower graph) of ristocetin in a 50- $\mu$ l mixture for $30 \mathrm{~min}$ at room temperature. The mixture was then vacuumdrawn through a nitrocellulose membrane containing the immobilized protein of serumfree culture medium harvested from pMW2transformed cells $(W T), \mathrm{pMW} 2 /$ G233V-transformed cells $(G 233 V)$, or non-

transformed $\mathrm{CHO}-\mathrm{K} 1$ cells. The membranes were dried without washing, and the bound radioactivity was determined as described in Fig. 2. Background binding obtained using nontransformed $\mathrm{CHO}-\mathrm{K} 1$ cell supernatant was subtracted from that value obtained using the culture medium from the two transformed cells lines. $O$, WT; $\Delta$, G233V.

regardless of the vWf concentration added (Fig. 3, lower graph). It is apparent from these assays that the binding curve generated for the mutant fragment, but not the normal fragment, is the same whether ristocetin is used at $0.34 \mathrm{mg} / \mathrm{ml}$ or 1 $\mathrm{mg} / \mathrm{ml}$ (compare the curves shown in the upper and lower graphs of Fig. 3). Thus, the phenotypic consequence of a Gly $^{233} \rightarrow$ Val substitution in the recombinant fragment is not an increased binding capacity for vWf, but an ability to bind a similar amount of $\mathrm{vWf}$ at a lower concentration of ristocetin.

\section{Discussion}

Under normal in vivo circumstances, the interaction between vWf and platelet GP Ib-IX is strictly regulated to occur only at those times required for the initiation of hemostasis. As an example of this regulation, soluble plasma vWf has an unmeasurable affinity for circulating platelets, yet the exposure of surface-bound vWf at a site of vascular injury is a crucial factor for supporting platelet adhesion via the GP Ib-IX complex ( 1 , $2,6)$. Two disease states, platelet-type von Willebrand disease and type IIB von Willebrand disease, have suggested that abnormalities in either the receptor or the ligand may support an interaction between soluble vWf and platelets with a sufficient affinity to promote intravascular platelet clumping, thrombocytopenia, and a resulting bleeding disorder.

Relevant to platelet-type von Willebrand disease, Miller et al. (12) identified an amino acid change at position 233 of the $\alpha$-subunit of GP Ib that was linked to inheritance of the platelet-type von Willebrand disease phenotype. Indeed, in vitro binding assays and studies using monoclonal antibodies have identified the binding site for vWf to be within the first 293 residues of GP Ib $\alpha(15,17)$, but the possible in vivo role of the other subunits of the complex, the $\beta$-chain of GP Ib and GP IX, in the modulation of binding to $\mathrm{vWf}$ has not yet been clarified. 
Thus, in the previously reported genetic analysis it was impossible to conclude that the Gly ${ }^{233} \rightarrow$ Val substitution is responsible for the abnormal GP Ib-IX complex and the propositus' reported phenotype. The results presented here establish that a recombinant GP Ib $\alpha$ fragment containing the single Gly ${ }^{233} \rightarrow$ Val substitution can mimic the phenotype originally described for platelet-type von Willebrand disease, namely the ability of platelets to interact with vWf at lower doses of ristocetin. These functional assays demonstrate that the Gly $^{233} \rightarrow$ Val substitution is the molecular basis of platelet-type von Willebrand disease in this family and further document the independent role of the $\alpha$-chain of GP Ib in modulating and supporting the binding of vWf to the platelet GP Ib-IX complex.

The vWf binding curves generated using the mutant recombinant fragment were similar regardless of whether binding was performed with $0.34 \mathrm{mg} / \mathrm{ml}$ or $1 \mathrm{mg} / \mathrm{ml}$ ristocetin (Fig. 3). This result implies that the functional $\mathrm{vWf}$ binding site within the mutant fragment is the same at both concentrations of ristocetin. This result is consistent with the interpretation that the mutations resulting in platelet-type von Willebrand disease are more likely related to "modulation" or "exposure" of other residues that constitute the direct contact sites with $\mathrm{vWf}$, rather than to changes of a contact site itself. According to this hypothesis, it would be expected that a number of different mutations within regions crucial for modulation could result in platelet-type von Willebrand disease. Supporting this hypothesis are preliminary reports linking an amino acid substitution at position 239 of GP Ib $\alpha$ (Met $\rightarrow$ Val) to the molecular defect within two different individuals with platelet-type von Willebrand disease $(22,23)$. Moreover, a number of different mutations resulting in the hyperfunctional ligand associated with type IIB von Willebrand disease have been identified and are clustered within the vWf domain containing the GP Ib-IX binding site $(9,24,25)$. Thus, although the genetic defects of platelet-type von Willebrand disease and type IIB von Willebrand disease appear to be heterogeneous, the mutations may be restricted to regions within each molecule important for the modulation of binding.

The use of botrocetin as a modulator of vWf binding to GP Ib did not reveal the platelet-type von Willebrand disease phenotype, nor has it been reported that it can diagnose the aberrant platelet receptor typical of the disease. It is known that distinct mechanisms of action underlie the modulating function of ristocetin and botrocetin (26), but how either experimentally induced binding mimics the in vivo interaction between vWf and GP Ib is not known. Botrocetin appears to exert its action on vWf generating a modulator-induced binding site for GP Ib-IX within the botrocetin-vWf complex $(27,28)$. In contrast, ristocetin-mediated binding seems to require an initial concentration-dependent dimerization of ristocetin that subsequently mediates a bifunctional bridging between $\mathbf{v W f}$ and GP Ib-IX dependent upon a ristocetin binding site within both the receptor and ligand (29). Thus, ristocetin highlights both the intrinsically increased affinity of mutant GP Ib $\alpha$ for normal vWf associated with platelet-type von Willebrand disease and the mutant vWf and normal GP Ib $\alpha$ associated with type IIB von Willebrand disease.

Previous studies have demonstrated a direct interaction between the mutant platelet receptor with a Gly ${ }^{233} \rightarrow$ Val substitution and soluble vWf $(12,30)$; in contrast, the mutant recombinant GP Ib $\alpha$ fragment showed no binding of vWf in the absence of modulators, although exhibiting the typical enhanced response to low concentrations of ristocetin seen in platelettype von Willebrand disease. This observation may be due to the fact that the $\mathrm{vWf}$ binding domain within the intact receptor complex on platelets is functionally different from that expressed in the isolated recombinant GP Ib $\alpha$ fragment due to the contribution of the other components of the complex (GP $\mathrm{Ib} \beta$, GP IX and, perhaps, GP V, in addition to the portion of GP Ib $\alpha$ chain not expressed in the recombiant fragment). Moreover, the presence of a second vWf receptor on the platelet surface, the GP IIb-IIIa complex, may be necessary to detect the direct $\mathrm{vWf}$ binding seen in the patients, since it is now known that binding to GP Ib results in activation of GP IIb-IIIa and concurrent binding of vWf to both receptors (5). Obviously, the contribution of GP IIb-IIIa is missing in our experimental assay with the isolated recombinant GP Ib $\alpha$ fragment. Nevertheless, our results prove that the enhanced response to low concentrations of ristocetin is exclusively the consequence of the Gly ${ }^{233} \rightarrow$ Val substitution.

Although the present results provide information relevant to platelet-type von Willebrand disease and the functional role of the $\mathrm{NH}_{2}$ terminus of GP Ib $\alpha$, it still remains to be established whether, in normal hemostasis, conformational changes within the receptor, the ligand, or both are required to generate the necessary affinities to support platelet adhesion. In fact, the true mechanisms may be even more complex to include factors such as rheological conditions or still undiscovered molecules, analogous to ristocetin and botrocetin, acting as in vivo modulators. However, definition of the molecular bases of platelettype von Willebrand disease and type IIB von Willebrand disease may help in identifying the essential mechanisms that control thrombus formation and may provide a better understanding of normal hemostasis and of those pathological situations culminating in the thrombotic occlusion of a blood vessel.

\section{Acknowledgments}

We would like to thank Jim Roberts for technical support; Eileen Bristow and Lynn LaCivita for secretarial assistance.

This work has been supported in part by National Institutes of Health grant HL-42846. The authors acknowledge the Sam and Rose Stein Trust Fund for establishing a DNA core facility to synthesize oligonucleotides within the Department of Molecular and Experimental Medicine at The Scripps Research Institute. This is manuscript 7305 from the Department of Molecular and Experimental Medicine/ Committee on Vascular Biology at The Scripps Research Institute.

\section{References}

1. Weiss, H. J., T. B. Tschopp, H. R. Baumgartner, I. I. Sussman, M. M. Johnson, and J. J. Egan. 1974. Decreased adhesion of giant (Bernard-Soulier) platelets to subendothelium. Further implications on the role of the von Willebrand factor in hemostasis. Am. J. Med. 57:920-925.

2. Weiss, H. J., V. T. Turitto, and H. R. Baumgartner. 1978. Effect of shear rate on platelet interaction with subendothelium in citrated and native blood. I. Shear rate-dependent decrease of adhesion in von Willebrand's disease and the Bernard-Soulier syndrome. J. Lab. Clin. Med. 92:750-764.

3. Castella, A., J. L. Miller, R. W. Neuberg, M. S. Gawryl, and L. W. Hoyer. 1983. Development of an inhibitor specific to factor VIII: coagulant activity in a patient with platelet-type von Willebrand's disease. Am. J. Clin. Pathol. 80:745749.

4. Ruggeri, Z. M., L. De Marco, L. Gatti, R. Bader, and R. R. Montgomery. 1983. Platelets have more than one binding site for von Willebrand factor. $J$. Clin. Invest. 72:1-12. 
5. Savage, B., S. J. Shattil, and Z. M. Ruggeri. 1992. Modulation of platelet function through adhesion receptors: a dual role for glycoprotein IIb-IIIa (integrin $\alpha_{\mathrm{IIB}} \beta_{3}$ ) mediated by fibrinogen and glycoprotein Ib-von Willebrand factor. $J$. Biol. Chem. 267:11300-11306.

6. Sakariassen, K. S., P. A. Bolhuis, and J. J. Sixma. 1979. Human blood platelet adhesion to artery subendothelium is mediated by factor VIII/von Willebrand factor bound to the subendothelium. Nature (Lond.). 279:636-638.

7. Ikeda, Y., M. Handa, K. Kawano, T. Kamata, M. Murata, Y. Araki, H. Anbo, Y. Kawai, K. Watanabe, I. Itagaki, K. Sakai, and Z. M. Ruggeri. 1991. The role of von Willebrand factor and fibrinogen in platelet aggregation under varying shear stress. J. Clin. Invest. 87:1234-1240.

8. Roth, G. J. 1991. Developing relationships: arterial platelet adhesion, glycoprotein Ib, and leucine-rich glycoproteins. Blood. 77:5-19.

9. Ware, J., J. A. Dent, H. Azuma, M. Sugimoto, P. A. Kyrle, A. Yoshioka, and Z. M. Ruggeri. 1991. Identification of a point mutation in Type IIB von Willebrand disease illustrating the regulation of von Willebrand factor affinity for the platelet GP Ib-IX receptor. Proc. Natl. Acad. Sci. USA. 88:2946-2950.

10. Miller, J. L., and A. Castella. 1982. Platelet-type von Willebrand's disease: characterization of a new bleeding disorder. Blood. 60:790-794.

11. Weiss, H. J., D. Meyer, R. Rabinowitz, G. Pietu, J. Girma, W. J. Vicic, and J. Rogers. 1982. Pseudo von Willebrand's disease: an intrinsic platelet defect with aggregation by unmodified human factor VIII/von Willebrand factor and enhanced adsorption of its high molecular weight multimers. N. Engl. J. Med. 306:326-333.

12. Miller, J. L., D. Cunningham, V. A. Lyle, and C. L. Finch. 1991. Mutation in the gene encoding the $\alpha$ chain of platelet glycoprotein Ib in platelet-type von Willebrand disease. Proc. Natl. Acad. Sci. USA. 88:4761-4765.

13. Vicente, V., R. A. Houghten, and Z. M. Ruggeri. 1990. Identification of a site in the alpha chain of platelet glycoprotein Ib that participates in von Willebrand factor binding. J. Biol. Chem. 265:274-280.

14. Ruggeri, Z. M. 1991. The platelet glycoprotein Ib-IX complex. In Progress in Hemostasis and Thrombosis. B. S. Coller, editor. W. B. Saunders Co., Philadelphia. $35-68$

15. Murata, M., J. Ware, and Z. M. Ruggeri. 1991. Site-directed mutagenesis of a soluble recombinant fragment of platelet glycoprotein $\mathrm{Ib} \alpha$ demonstrating negatively charged residues involved in von Willebrand factor binding. J. Biol. Chem. 266:15474-15480.

16. Handa, M., K. Titani, L. Z. Holland, J. R. Roberts, and Z. M. Ruggeri. 1986. The von Willebrand factor-binding domain of platelet membrane glycoprotein Ib. Characterization by monoclonal antibodies and partial amino acid sequence analysis of proteolytic fragments. J. Biol. Chem. 261:12579-12585.

17. Vicente, V., P. J. Kostel, and Z. M. Ruggeri. 1988. Isolation and functional characterization of the von Willebrand factor-binding domain located be- tween residues His(1)-Arg(293) of the alpha-chain of glycoprotein Ib. J. Biol. Chem. 263:18473-18479.

18. Seed, B. 1987. An LFA-3 cDNA encodes a phospholipid-linked membrane protein homologous to its receptor CD2. Nature (Lond.). 329:840-842.

19. Kunkel, T. A., J. D. Roberts, and R. A. Zakour. 1987. Rapid and efficient site-specific mutagenesis without phenotypic selection. Methods Enzymol. 154:367-383.

20. Chen, C., and H. Okayama. 1987. High-efficiency transformation of mammalian cells by plasmid DNA. Mol. Cell. Biol. 7:2745-2752.

21. Fraker, P. J., and J. C. Speck. 1978. Protein and cell membrane iodinations with a sparingly soluble chloramide, 1,3,4,6-tetrachloro-3a, 6a-diphenylglycoluril. Biochem. Biophys. Res. Commun. 80:849-857.

22. Russell, S. D., and G. J. Roth. 1991. A mutation in the platelet glycoprotein (GP) $\mathrm{Ib} \alpha$ gene associated with pseudo-von Willebrand disease. Blood. 78(Suppl. 1):281a. (Abstr.)

23. Takahashi, H., M. Murata, T. Furukawa, M. Handa, K. Watanabe, and Y. Ikeda. 1992. A point mutation in gene encoding gyloprotein $\mathrm{Ib} \alpha$ in a Japanese family with platelet-type von Willebrand disease. Blood. 80:130a

24. Cooney, K. A., W. C. Nichols, M. E. Bruck, W. F. Bahou, A. D. Shapiro, E. J. W. Bowie, H. R. Gralnick, and D. Ginsburg. 1991. The molecular defect in type IIB von Willebrand disease. Identification of four potential missense mutations within the putative GPIb binding domain. J. Clin. Invest. 87:1227-1233.

25. Randi, A. M., I. Rabinowitz, D. J. Mancuso, P. M. Mannucci, and J. E. Sadler. 1991. Molecular basis of von Willebrand disease type IIB. Candidate mutations cluster in one disulfide loop between proposed platelet glycoproteins Ib binding sequences. J. Clin. Invest. 87:1220-1226.

26. Girma, J. P., Y. Takahashi, A. Yoshioka, J. Diaz, and D. Meyer. 1990 Ristocetin and botrocetin involve two distinct domains of von Willebrand factor for binding to platelet membrane glycoprotein Ib. Thromb. Haemostasis. 64:326-332.

27. Read, M. S., S. V. Smith, M. A. Lamb, and K. M. Brinkhous. 1989. Role of botrocetin in platelet agglutination: formation of an activated complex of botrocetin and von Willebrand factor. Blood. 74:1031-1035.

28. Sugimoto, M., H. Mohri, R. A. McClintock, and Z. M. Ruggeri. 1991. Identification of discontinuous von Willebrand factor sequences involved in complex formation with botrocetin: a model for the regulation of von Willebrand factor binding to platelet glycoprotein Ib. J. Biol. Chem. 266:18172-18178.

29. Scott, J. P., R. R. Montgomery, and G. S. Retzinger. 1991. Dimeric ristocetin flocculates proteins, binds to platelets, and mediates von Willebrand factor-dependent agglutination of platelets. J. Biol. Chem. 266:8149-8155.

30. Miller, J. L., J. M. Kupinski, A. Castella, and Z. M. Ruggeri. 1983. von Willebrand factor binds to platelets and induces aggregation in platelet-type but not type IIB von Willebrand disease. J. Clin. Invest. 72:1532-1542. 